\title{
ELEMENTOS ÉTICOS NO DESENVOLVIMENTO DO CÓDIGO DE CONDUTA PARA IMPLEMENTAÇÃO DE UM PROGRAMA DE COMPLIANCE
}

\author{
Fernando Medeiros Costa \\ Nilton Carvalho Lima De Medeiros
}

\section{RESUMO}

Muitos foram os casos em que houve falhas a partir de condutas que feriram a ética. Com base nos casos narrados, o presente trabalho tem por escopo o desenvolvimento do debate entre elementos éticos, com indicação de ferramentas filosóficas que possam ser úteis na elaboração de códigos de conduta, destacando ganhos para os mais diversos setores, bem como aos indivíduos que façam parte, além da coletividade. Para tanto, foram analisadas alterações legislativas para que as atividades atuem em conformidade com padrões éticos contemporâneos.

Palavras-chave: Compliance. Integridade. Eficiência.

\section{ETHICAL ELEMENTS IN THE DEVELOPMENT OF THE CODE OF CONDUCT FOR THE IMPLEMENTATION OF A COMPLIANCE PROGRAM}

\begin{abstract}
Many were the cases in which there was failures from condut that disajust ethics. Based on the narrated cases, the presente article has as scope the development of the debate among ethical elements, with indication of philosophical tools that can be useful in the elaboration of conduct's code, highlighting gains of the most diverse sectors, as well as to the of the individuals that participates, in addition to collectivity. In order to do so, legislative changes were analyzed so that the activities act in accordance with contemporary ethical standards.
\end{abstract}

Key-words: Compliance. Integrity. Eficiency.

\section{INTRODUÇÃO}

Alguns escândalos de corrupção internacional fizeram surgir a demanda de busca por um ambiente de negócios mais ético. O caso conhecido por "Water Gate", que culminou com a renúncia do ex-presidente norte-americano Richard Nixon, acusado de interferir em investigações para obstaculizar a identificação dos envolvidos em um caso de espionagem eleitoral, em sua segunda eleição, é considerado um marco para tal.

Após o escândalo de natureza eleitoral, e do surgimento dos denominados crimes macroeconômicos, identificou-se o surgimento no poder legislativo norte-americano de um movimento de preocupação com o combate à corrupção e em especial a esta modalidade de crimes, o que culminou com a edição do instrumento legislativo de combate à corrupção de agentes públicos estrangeiros, a denominada "Foreign Corrupt Practices Act", a qual chamaremos de FCPA. 
Após a edição deste instrumento normativo e com isto a preocupação das empresas em adequar-se à inovação no ordenamento jurídico na época, instrumentos e ferramentas foram criadas pelas organizações para buscar atender aos regramentos de integridade ali inseridos, fazendo surgir a expressão "Compliance".

Utilizada hoje no Brasil, sem espanto apesar do estrangeirismo, a mesma refere-se à prática de estar em conformidade com as leis e regras aplicáveis às organizações, e tem origem na expressão, em inglês, "to comply with" que significa estar de acordo com uma norma ou conduta vista por adequada.

Seguindo este panorama de busca por um ambiente mais ético a Convenção Interamericana contra a Corrupção criada pela OEA- Organização dos Estados Americanos, firmada em 1996, foi aprovada no Brasil pelo Decreto Legislativo n. ${ }^{\circ}$ 152/2002 e Decreto Presidencial n. ${ }^{\circ} 4.410 / 2002^{1}$.

No mesmo sentido de aperfeiçoamento do ambiente negocial e efetivação do combate à corrupção, a Convenção sobre o Combate da Corrupção de Funcionários Públicos Estrangeiros em Transações Comerciais, criado pela Organização para a Cooperação e Desenvolvimento Econômico (“OCDE”) foi aprovada no Brasil, foi aprovada pelo Decreto

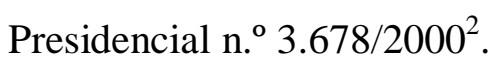

Outro grande marco para a efetivação do combate à corrupção foi a Convenção da ONU - Organização das Nações Unidas sobre a Corrupção adotada pela Assembleia Geral de 31 de outubro de 2003, aprovada pelo Decreto Legislativo n. ${ }^{\circ}$ 348/2005 e Decreto Presidencial n. ${ }^{\circ} 5.687 / 2006^{3}$.

Com a aprovação de referida convenção pelo poder executivo e legislativo brasileiro, o país comprometeu-se a formular e aplicar ou manter em vigor políticas coordenadas e eficazes contra a corrupção, além de estabelecer e fomentar práticas eficazes encaminhadas a prevenir a corrupção.

\footnotetext{
${ }^{1}$ Decreto ${ }^{\circ} 4.410$, de 7 de outubro de 2002. Promulga a Convenção Interamericana contra a Corrupção, com reserva para o art. XI, parágrafo 1o, inciso "c", adotada em Caracas, em 29 de março de 1996. Diário Oficial da União da República Federativa do Brasil, Brasília, DF, 8 de outubro de 2002.

${ }^{2}$ Decreto $n^{\circ} 3.678$, de 30 de novembro de 2000. Promulga a Convenção sobre o Combate da Corrupção de Funcionários Públicos Estrangeiros em Transações Internacionais, concluída em Paris, em 17 de dezembro de 1997. Diário Oficial da União da República Federativa do Brasil, Brasília, DF, 1º de dezembro de 2000.

${ }^{3}$ Decreto ${ }^{\circ}$ 5.687, de 31 de janeiro de 2006. Promulga a Convenção das Nações Unidas contra a Corrupção, adotada pela Assembleia-Geral das Nações Unidas em 31 de outubro de 2003. Diário Oficial da União da República Federativa do Brasil, Brasília, DF, 1º de fevereiro de 2006.
} 
Em resposta a este compromisso, o Congresso Brasileiro aprovou em $1^{\circ}$ de agosto de 2013 a Lei 12.846 a qual dispõe sobre a responsabilização administrativa e civil de pessoas jurídicas pela prática de atos contra a administração pública, nacional ou estrangeira.

Nestas circunstâncias, as empresas brasileiras, que já eram pressionadas pelas estrangeiras à busca por uma atuação mais ética, viram-se obrigadas por meio de referida norma a buscarem elidir atos corruptivos sob pena de serem severamente punidas, com multas entre $0,1 \%$ a $20 \%$ do faturamento do ano anterior à abertura do Processo Administrativo de Responsabilização prevista nessa lei, além do dever de ressarcir os cofres públicos dos danos causados e outras punições.

Neste cenário, diversas empresas passaram a buscar implementar programas de Compliance com o escopo de instaurar um ambiente de negócios mais integro. Por mais que uma empresa possa ter primazia sobre as outras em determinado mercado, o acompanhamento e desenvolvimento de ferramentas que possam atestar práticas saudáveis de competição irão contribuir para a sociedade e para todas as empresas.

Definir e acompanhar padrões de integridade não devem ser vistos como um direito para pequenas empresas ou empresas que tenham baixa fatia de mercado. Nenhuma empresa terá o domínio de um mercado por toda sua existência. Ainda que tivesse, poderia perder significativa participação empresarial, caso empresas pudessem baixar significativamente seus custos por práticas danosas à concorrência. Desta forma, entende-se que o monitoramento das práticas empresariais beneficiam todas as empresas, independente da força de mercado e tamanho de suas organizações. São práticas que objetivam manter a integridade de todo o mercado, favorecendo todas as empresas sem exceção, garantindo segurança e transparência nas relações organizacionais.

Nesta busca pela então chamada ética empresarial, surge a necessidade de realizar o debate sobre tais questões, as quais podem ser realizadas sobre os mais diversos campos, nas mais variadas profissões, organizações, famílias, Estados, esportes, dentre tantos outros. Sabese os inúmeros debates e distinções que ocorrem entre ética e moral, no entanto, para o presente trabalho, não haverá distinção na utilização destes conceitos, até porque, "o ético transforma-se assim numa espécie de legislador do comportamento moral dos indivíduos ou da comunidade" (VÁZQUEZ, 2003, p. 20).

As discussões influenciam no desenvolvimento das sociedades, na orientação para construção das normas jurídicas, bem como, sofre influencia de todos essas campos. Não podemos dizer que as normas éticas possuem construção independente e passam a irradiar 
sobre todos os outros campos, mantendo-se inerte. Da mesma forma que realiza influência, passa a ser alterada a partir do momento que passa a interagir.

A competição, busca pelo predomínio, atingimento de marcas de desempenho, inovações, devem ocorrer a partir de padrões estabelecidos, de maneira que não se anule concorrentes, nem prejudique mercados e atores envolvidos neste processo.

Existe, antes de tudo, um elemento discursivo de mútua influência, como os demais elementos que compõem a sociedade. Conforme será visto, o elemento comunicacional possui importância na formulação de debates éticos, bem como, na construção de códigos de conduta.

A fim de iniciar o debate, deve-se perceber que o objetivo em se analisar o campo ético no ambiente organizacional é a melhoria da eficiência, minimização de prejuízos e aperfeiçoamento de processos que, ao final, constata-se por evitar conflitos e a melhora operacionalmente das atividades.

Não está-se dizendo que uma análise ética possa resolver mas será, certamente, uma ferramenta para otimizar resultados com diminuição de perdas, seja pelo melhor trato interpessoal, seja pelo ganho em eficiência e foco no desempenho da atividade.

O objetivo deste ensaio é debater a influência que o estudo da ética tem sobre a estruturação de um programa de compliance. Esta influência não deve ser vista como um feio ao desenvolvimento de mercados, mas uma orientação de como este deve ser fruir, com a previsibilidade e impedimento de práticas que venham a ferir o bom andamento dos mercados.

Pretende-se investigar, em especial, a possibilidade da interferência da perturbação externa oriunda da imposição de condutas condizentes com os valores da empresa à mudança individual dos membros da companhia.

Serão, assim, analisados os elementos que caracterizam um código de conduta e um programa de compliance, verificar-se-á se as normas éticas impostas aos membros de uma organização empresarial seriam capazes de conduzir a uma mudança comportamental do indivíduo que transcende ao simples cumprimento das normas da empresa previstas neste programa.

Inicialmente fez-se breve abordagem das características de um código de conduta e de um programa de compliance. Em seguida, buscou-se apresentar esta norma de conduta interna da organização como perturbação externa capaz de mudar internamente os valores do indivíduo. 
A pesquisa, de viés qualitativo e de cunho exploratório, será lastreada em levantamento bibliográfico.

\title{
2 O PROGRAMA DE COMPLIANCE E O CÓdigo DE CONDUTA COMO ELEMENTO DE MUDANÇA DE VALORES ÉTICOS DA SOCIEDADE
}

Nas linhas acima, delineou-se o panorama internacional que preconizou o robustecimento desta preocupação com um ambiente de negócios mais íntegro, o qual foi sentido inicialmente pelas empresas brasileiras que detinham negócios com organizações de outras nações. Com a entrada em vigor da Lei $12.846 / 13^{4}$, a necessidade de implementação de um programa de compliance transcendeu às empresas com relações internacionais, passando a ser imperativa para todas as empresas nacionais.

Com o robustecimento desta busca por um ambiente de negócio mais íntegros o escopo do programa de compliance não mais se limitou ao cumprimento do ordenamento jurídico nacional e internacional, mas passou a preocupar-se em adoção de medidas de governança corporativa capazes de trazer um ambiente negocial mais ético, Ribeiro (2015, p 88):

\begin{abstract}
Não se pode confundir o Compliance com o mero cumprimento de regras formais e informais, sendo o seu alcance bem mais amplo, ou seja, "é um conjunto de regras, padrões, procedimentos éticos e legais, que, uma vez definido e implantado, será a linha mestra que orientará o comportamento da instituição no mercado em que atua, bem como a atitude dos seus funcionários" (CANDELORO; RIZZO; PINHO, 2012, p. 30). Será instrumento responsável pelo controle dos riscos legais ou regulatórios 1 e de reputação, devendo tal função ser exercida por um Compliance Officer2, o qual deve ser independente e ter acesso direto ao Conselho de Administração.3 O Compliance envolve questão estratégica e se aplica a todos os tipos de organização, visto que o mercado tende a exigir cada vez mais condutas legais e éticas, para a consolidação de um novo comportamento por parte das empresas, que devem buscar lucratividade de forma sustentável, focando no desenvolvimento econômico e socioambiental na condução dos seus negócios.
\end{abstract}

Com o novo escopo trazido aos programas de compliance, o Código de Conduta ganhou ainda mais relevância, pois este, que já era considerado a ferramenta principal do programa de integridade, passou a ser visto como meio de transmissão de valores da empresa aos indivíduos que faziam parte daquelas organizações de forma a de forma abrangente, trazer benefícios estratégicos à empresa.

\footnotetext{
${ }^{4}$ Dispõe sobre a responsabilização administrativa e civil de pessoas jurídicas pela prática de atos contra a administração pública, nacional ou estrangeira, e dá outras providências.
} 
O código de conduta será o principal documento do programa de compliance, pois nele estarão inseridos os valores que guia a corporação e serão impostos a todos os funcionários, fornecedores, parceiros e quaisquer outras organizações e pessoas que se relacionem com a empresa,

Um código de conduta28 é um documento empresarial que traduz uma política da empresa referente a condições de trabalho. O documento tem publicidade e tais condições de trabalho serão impostas aos fornecedores, intermediários e, mesmo, consumidores. Trata-se de um documento formalmente adotado pela empresa ou instituição, como diretriz a ser seguida por todos os seus funcionários29. Um código de conduta é uma declaração formal de valores e práticas corporativas.

O Programa de Compliance, portanto, terá como um de seus objetivos, por meio do código de conduta, principais transferir a todos os que compõem a empresa a missão, a visão e os valores daquela, almejando que estes sejam assimilados e absorvidos pelos que compõem a companhia e passem a agir de forma mais íntegra nas relações interpessoais ao representarem a organização.

A ética divide-se em ética de consciência e ética de responsabilização, sendo a primeira pautada por princípios e valores intrínsecos ao indivíduo, que fazem com que sua ações sejam moldadas pela sua conscientização do que é certo ou errado, e a segunda, a através da qual o indivíduo avalia os riscos oriundos da adoção daquela medida, pensando nas consequências que a realização do atro lhe trarão. (Weber, 1963, 97 - 153).

Originalmente, o programa de compliance teria como objetivo buscar conduzir os que fazem a companhia a seguirem os valores desta para a ética de responsabilização, ou seja, ainda que discordassem de tais valores, para que não fossem responsabilizados pelo descumprimento de norma internas da empresa, ou da legislação vigente, adotariam as condutas ali designadas.

Para Maturama (1995, p. 95), todo organismo, ao ser exposto a uma perturbação externa sofre modificações em sua estrutura interna transformando-se, neste sentido, entendendo ser o Código de Conduta e as ferramentas que constituem um programa de compliance uma perturbação externa que busca induzir a uma postura de respeito ao ordenamento jurídico, bem como a adoção de posturas éticas, este regramento empresarial interno seria capaz de modificar valores dos indivíduos a eles submetidos levando-os a uma conduta mais ética ainda que em relações que transcendessem o ambiente empresarial. 
O programa de compliance, por meio do código de conduta, traria vantagens à organização e à sociedade que transcenderiam o simples cumprimento do ordenamento jurídico, para Ribeiro (2015, p. 12-15),

Enfim, uma vez implantada a política e funcionando de forma efetiva, a empresa tende a obter mais confiança dos investidores e maior credibilidade no mercado. Assim, alcançará altos níveis de cooperação interna e externa, com consequente aumento de lucro, mas sempre de forma sustentável, trazendo benefícios à organização, a seus empregados e à sociedade.

A perspectiva de alteração de valores internos do indivíduo ao assimilar valores de integridade da corporação à qual está vinculado, transcenderia, portanto, as vantagens a serem auferidas tão somente pela organização, mas admitidos os valores inicialmente incutidos pela empresa como, então, do indivíduo.

Essa mudança de qualidade de elemento de ética externa, ou de responsabilização, baseada na preocupação das consequências dos atos, para uma ética interna, de consciência, enraizada, agora, nestes novos valores teria consequências na consciência do mesmo que passaria a dotar estes valores como seus, para a tomada das suas decisões.

As balizas de elementos éticos que antes norteavam as decisões do indivíduos e que muitas vezes tangenciavam com a ilicitude, uma vez absorvidos os valores presentes no código de conduta, dão lugar a novos elementos éticos que conduzirão a vida do indivíduo, fazendo com que este já não mais se aproveite das oportunidades de cunho exploratório de outros indivíduo, bem como muitas vezes tenha uma nova abordagem em sua própria estrutura familiar no que tange a elementos morais.

\section{A ANÁLISE DE ELEMENTOS ÉTICOS NA CONDUTA DOS SUJEITOS}

O debate sobre a ética realiza-se com o intuito de orientar em como as escolhas devam ser realizadas. Um aspecto interessante a ser abordado é a liberdade no desenvolvimento da atividade profissional. Liberdade não deve ser confundida com respeito ou confiança no ambiente organizacional. A confiança existe no momento em que as partes passam a interagir em conjunto através do vínculo laboral, portanto, pode ser interpretada sob os mais diversos campos.

O desenvolvimento de uma atividade profissional, pressupõe certa margem de liberdade para inovar, aprimorar processos, minimizar custos e tempo para produção. Ocorre 
que, como em toda atividade, nenhum sujeito deve ser livre para escolher como bem entender a forma de realizar sua atividade.

O debate sobre o código de conduta é exatamente a antecipação racional e negociada de condutas que auxiliem no desenvolvimento laboral mas, principalmente proibição de condutas que possam prejudicar em elevados patamares a atividade organizacional.

A liberdade definida através de limites éticos será aquela que, respeitando a subjetividade, criatividade e capacidade de inovação, não venha a prejudicar a atividade em sua globalidade.

Note-se que não há aqui nenhuma tentativa de restrição, limitação do desenvolvimento ou da proatividade. Os procedimentos passam a ser desenvolvidos em grande escala, com uma maior participação de setores e equipes. A autonomia ocorre de maneira que se respeite a atuação e liberdade de cada um, sem comprometer o processo produtivo.

Quando existe autonomia irrestrita, a comunicação dificulta a atuação em equipe e, com o nível de especialização que temos, é preciso que se observe uma padronização de condutas como forma de viabilizar a atuação entre os membros.

A análise e fixação destas normas de condutas não deve ser entendida como a soma das vontades. No momento em que se vota, é comum que existam votos distintos, com as mais diversas justificativas. O objetivo é que haja, na medida do possível, um unanimidade nas escolhas para manter a unidade dos atos e escolhas que irão ser realizadas no desempenho das mais diversas funções. É neste momento que a negociação, fundamentação e debate ganham importância, para que se chegue a uma solução negociada.

Cada escolha realizada, minimiza a possibilidade de erros, por decisões equivocadamente realizadas. No momento da tomada de decisão, não há como prever todos os dilemas aos quais nos deparamos, no entanto, como o debate a ser realizado é feito por que exerce as atividades, pode-se, na medida do possível, antecipar grandes impasses, debater e solucioná-los.

Pode-se questionar a real necessidade de um código de condutas, tendo em vista a existência de uma ampla legislação com proibições, autorizações e obrigações sobre as mais diversas condutas que deve nortear a sociedade, como ocorre com as normas jurídicas. Para LUMIA (2003, p. 44), “[...] todos os ordenamentos jurídicos contêm normas que impõem obrigações (imperativos positivos) e normas que estabelecem proibições (imperativos negativos). Mas, ao lado dessas normas existem outras que contêm permissões". 
Uma importante diretriz jurídica é o princípio da autonomia da vontade. Ao particular é conferido o direito de realizar tudo aquilo que não for proibido por lei. Desta forma, existe uma grande amplitude de atuação. O Estado, através do seu poder de legislar, não desce a minúcias para regular a vida cotidiana na esfera privada. Os particulares possuem esse poder de negociação em estipular e agir dentro do espaço de liberdade conferido pelo Direito. Para Bobbio (1999, p. 40),

\begin{abstract}
Outra fonte de normas de um ordenamento jurídico é o poder atribuído aos particulares de regular, mediante atos voluntários, os próprios interesses: trata-se do chamado poder de negociação. O enquadramento dessa fonte na classe das fontes reconhecidas ou na das fontes delegadas é menos nítido. Se se coloca em destaque a autonomia privada, entendida como capacidade dos particulares de dar normas a si próprios numa certa esfera de interesses, e se considerarmos os particulares como constituintes de um ordenamento jurídico menor, absorvido pelo ordenamento estatal, essa vasta fonte de normas jurídicas é concebida de preferencia como produtora independente de regras de conduta que são aceitas pelo Estado.
\end{abstract}

É importante observar o que está no campo da legislação ordinária e o que vem a ser tratado nos programas de compliance. O que vem a ser positivado é o que o Estado entende algo como obrigatório, como proibido, ou quando sente necessidade em delimitar as possibilidades que um ato deve conter.

Nem todo ato adequado ao convívio social necessariamente virá a ser tratado pelo legislador. Através da evolução social, muitos atos que estavam sob a análise moral vieram a se tornar jurídicos, mas nem todos. O campo para o debate ético nasce exatamente em condutas que, apesar de favorecerem um adequado desenvolvimento social, não foram incluídas pela obrigatoriedade ou proibição pela via legislativa.

Desta feita, com um amplo espaço para atuação, as organizações passam a detalhar e antecipar decisões em seus códigos de condutas. Mesmo que exista uma amplitude de atuação, nem todas as decisões licitamente disponíveis, poderão ser gerencialmente adequadas.

Também não seria o caso em se estipular um código de condutas geral para todas as atividades. Este passa a variar conforme a atividade, mercado e cultura empresarial, razão pela qual, cada entidade deva individualizar suas próprias regras.

\title{
4 A INFLUÊNCIA DA ÉTICA NAS RELAÇÕES ORGANIZACIONAIS
}


Para delimitar uma primeira grande influência, deve-se constatar que decisões éticas devem ocorrer por razões válidas sendo, portanto, diferente de escolhas, interesses ou gostos. A imparcialidade contribui para que boas decisões sejam tomadas.

Cada indivíduo comporta-se de maneira diferente, possui gostos distintos, o que não deve influenciar nas decisões que precisam ser realizadas organizacionalmente. A pluralidade é algo presente e positivo neste ambiente. O que se deve evitar sejam escolhas motivadas por interesses particulares (CORTINA, 2010, p. 271). Para James Rachels (2006, p. 13),

\footnotetext{
Ademais, não há implicações de que todos devem se sentir da mesma forma; se todo mundo odeia café, não importa. Por outro lado, se alguém diz que algo é moralmente errado, ele sim precisa de razões, e, se estas forem sólidas, as pessoas devem reconhecer sua força. De acordo com a mesma lógica, se ele não possui boas razões para o que diz, está simplesmente fazendo barulho e não precisamos prestar atenção.

Obviamente, nem todas as razões que podem ser desenvolvidas são válidas. Existem argumentos bons e ruins, e muito da habilidade do pensamento moral consiste em discernir a diferença.

$[\ldots]$

A primeira coisa é entender os fatos corretamente. [...]. Outro problema é o preconceito humano. Muitas vezes queremos acreditar em alguma versão dos fatos, porque ela fundamenta nossos preconceitos.
}

Por preconceito, deve-se entender os pré-conceitos, ou seja, conceitos prévios que adquirimos no curso de nossa vida através de nossas vivencias. Isso quer dizer que não devemos pautar nossas escolhas por interesses ou por pensamentos previamente constituídos. Devemos visualizar e escolher a partir daquilo que é formulado para que as escolhas sejam as mais imparciais e racionalmente válidas.

Escolhas e interpretações quando feitas de maneira privada, interna, possuem o condão de nos favorecer ou desvirtuar a implementação de algo. A preocupação com a atuação ética é exatamente sair do campo privado para o coletivo. É aceitar a prática ou a abstenção de condutas que, por mais possam ser contrárias ao entendimento particular, possam contribuir para a estabilidade e bom andamento da atuação pública.

Quando a possibilidade de escolhas é elevada a um grau coletivo, além de evitar ou minimizar escolhas com bases em interpretações privadas, busca-se maior eficiência que essas escolhas possam proporcionar, uma vez que estão indicadas em um patamar comunicacional, onde é possível o debate e o melhor entendimento sobre escolhas que devam ser tomadas no curso da atuação dos indivíduos. 
O que se pretende é a manutenção de uma estabilidade pública pela verificação e acompanhamento de condutas particulares que, pela via reflexa, virá a favorecer e manter a integridade dos direitos de cada organização.

Assim, não devemos decidir por "verdades" pré-concebidas, mas pelo resultado do debate, das razões apresentadas e entendidas como válidas. A diversidade de olhares, com razões diversas, tem-se que direcionar para aquelas que entendemos ser as razões válidas que devem prevalecer. Para Rachels (2006, p. 42),

\begin{abstract}
Por conseguinte, se quisermos entender a natureza da ética, devemos nos concentrar nas razões. A verdade da ética é uma conclusão que é respaldada pelas razões. A resposta correta para uma questão ética é simplesmente a resposta que possui o peso da razão a seu lado. Tais verdades são objetivas no sentido de que são verdadeiras independente do que queremos ou pensamos. Não podemos fazer com que algo seja bom ou ruim apenas almejando isso, porque não podemos meramente desejar que $o$ peso da razão esteja a favor ou contra isso. E assim, também se explica a nossa falibilidade: podemos estar errados a respeito do que é bom ou ruim porque podemos estar errados em relação ao que a razão sugere. A razão diz por si própria, independente da nossa opinião ou desejo.
\end{abstract}

A solução a que se quer decidir, não é algo aleatório que por acaso tenha sido escolhido, mas uma resposta dialogada e racionalmente escolhida como aquela capaz de atingir a melhor finalidade, sob o questionamento dos mais diversos participantes.

Deve-se também salientar uma grande distinção entre a realização de normas jurídicas e normas de conduta. As primeiras, são realizadas pelo critério majoritário em que, de maneira simplificada, somos instados a nos manifestar pela via direta ou indireta, os destinos e escolhas a serem atribuídos pelo Estado.

Na norma de conduta, temos uma constituição diversa. Deve existir a participação efetiva daqueles que estarão obrigados a cumprir tais normas, no entanto, além do debate realizado também pelas normas jurídicas, deve-se se ter um elemento racional, apresentando fortes razões para o adimplemento, evitando-se condutas diversas.

Para ficar clara a distinção, imagine-se a realização de uma norma jurídica, de maneira simplificada. Apresenta-se projeto de lei, define-se relator e revisor, debate-se no Congresso Nacional a importância de tal medida, aprovando-se pelo voto da maioria. Sabidamente o processo legislativo é mais complexo do que aqui relatado, no entanto, não há necessidade de detalhamento para o exemplo proposto.

Com o quórum para aprovação, o projeto é aprovado e, após sanção presidencial, e publicação, passa a vigorar em todo o país. Vários parlamentares certamente discordaram de 
tal medida, entenderam desnecessária mas, atingido o quórum para aprovação, esta etapa no legislativo está superada. O não cumprimento desta norma, resguardados os casos autorizados em lei, acarretará a aplicação de sanção.

No código de conduta este processo acontece de maneira diversa. A semelhança está na participação e debate, no entanto, o elemento comunicacional é relevante para que se apresente razões e importância de cada conduta. O objetivo principal é, dadas as razões de maneira inconteste àqueles que devem cumprir o regramento, minimiza-se a possibilidade do não adimplemento.

Com isso, demonstra-se a grande importância na produção e debate do código de condutas. Não se satisfaz com a constatação que muitos vão descumprir, tendo a aplicação de sanções como ocorre na norma jurídico.

Objetiva-se o mínimo de condutas desviantes, dada a nocividade e prejuízo que possa causar. Com o debate, escolhas racionais dialeticamente, pode-se chegar a uma universalização destas condutas dentro de uma organização. Como dito, isto contribuirá com a eficiência. Em uma sociedade, condutas desviantes não possuem grande impacto, pela escala em que se realiza dado o tamanho da sociedade, e o impacto pequeno no andamento das atividades diárias. Em uma organização, com escala reduzida e necessidade de atuar com finalidades definidas, o impacto é elevado.

Outro fator relevante é a possibilidade de revisão de condutas e processos. Por mais que escolhas sejam feito de maneira racional, esta realidade é sempre referente a um dado momento. Em havendo modificação desta realidade, aprimoramentos e novos debates, deve haver espaço para que se possa fazer a revisão destes processos, através de uma cooperação permanente.

Conforme visto, são três os fatores que devem ser atribuídos na decisão sobre o código de condutas: o acordo entre os participantes, a enumeração das razões em como agir, e a fundamentação na atuação para que a melhor razão possa ser atribuída, entendendo esta como aceitável no caso particular. Para Klaus Günther (2004, p. 365),

Esse princípio moral somente poderá ser aplicado como regra de argumentação em discursos, nos quais a potencial generalização dos interesses expressa na aceitabilidade das razões, apresentadas por participantes de direitos iguais. A aceitabilidade de boas razões não implica, entretanto, motivo algum para efetivamente observar a norma fundamentada nesse sentido. Razões, racionalmente aceitáveis, possuem, em virtude do seu pleito de obrigatoriedade, uma relevância imediata para a orientação efetiva da ação, não podendo, porém, produzir, a partir da 
sua própria capacidade, uma orientação correspondente à ação. Quem, ao agir, orientar-se de modo diferente simplesmente não possui boas razões.

Se discursos de aplicação, segundo a tese aqui debatida, fizerem parte da razão prática, o problema da motivação subsiste, de modo semelhante, tanto para a observância de normas válidas, quanto para a concretização de preceitos adequados de normas singulares. Em discursos de fundamentação e de aplicação, poderemos descobrir o que devemos fazer aqui e agora.

A solução é antes de tudo, uma resposta dialogada atribuindo uma razão aceitável. Por mais que alguém tenha experiência e habilidade em propor soluções, não há como cada um tomar decisões individuais, podendo prejudicar a atuação dos demais agentes. Com isso, algumas escolhas devam ser realizadas de maneira a ser seguidas por todo um conjunto de indivíduos, exigindo a participação e debate, produzindo escolhas mais acertadas e eficientes, contribuindo com as melhores práticas, integrando e evitando incompatibilidades na comunicação e atuação em coletividade.

\section{CONCLUSÃO}

Os estudos sobre os programas de compliance e o código de conduta têm enorme importância no panorama jurídico do país, uma vez que mesmo já estando o conceito e formatação jurídica deste instituto amplamente aplicado nacional e internacionalmente, bem como sendo a discussão já aceita pelos tribunais pátrios, por falta de estudo aprofundado, deixa muitas dúvidas, causando ainda hoje equívocos de conceituação e tratamento.

Os programas de compliance, como já esclarecido, ainda que tenham surgido sob o escopo de cumprir regulamentos internacionais anticorrupção com o poder público, sofreram um robustecimento em seu grau de importância e abrangência.

Com a aproximação entre as governança corporativa e os operadores do direito passou a compreender a necessidade de atuação simbiótica destes setores dentro das corporações com o objetivo de garantir maior grau de efetividade à mitigação de riscos de corrupção, percebeu-se que a atuação conjunta da gestão empresarial ao setoria de mitigação de riscos jurídicos podia ter consequências ainda mais positivas às empresas.

Esta atuação em paralelo e coparticipação criou programas de compliance com maior capilaridade dentro das companhias os quais trouxeram outros pontos de preocupação que iam além dos descumprimentos de regulamentos normativos e normas penais, mas passavam por condutas internas, muitas vezes despercebidas pela alta gestão, as quais, mesmo que não 
trouxessem riscos empresariais, mostravam-se contraproducentes ou mesmos gerencialmente arriscadas.

Os programas de compliance evoluíram, portanto, para além da busca por condutas lícitas, passando o seu escopo a fiscalizar, incentivar, induzir e garantir uma atuação de todos os que fazem as organizações em adequação às melhores práticas de governança corporativa com o objetivo de uma atuação mais ética que traz consigo um maior grau de confiabilidade à corporação além de buscar um ambiente de negócios íntegro e de certa maneira mais previsível.

A estruturação destes programas teve por ponto central a criação de códigos de condutas que transmitiam às diversas linhas de atuação das organizações os valores da empresa, os quais deveriam ser seguidos pela alta diretoria da empresa, passando pelos funcionários de chão de fábrica, além dos de linha de frente comercial e todos os parceiros, terceirizados e quaisquer outros que tivessem ligação ainda que indireta com a cadeia produtiva das empresas.

$\mathrm{Na}$ linha de análise dessa transmissão de valores, identificou-se, que o código de conduta, e sua função de transmitir valores, poderiam ser vistos como a perturbação externa mencionada por Humerto Maturama (1995, p. 95), que é capaz de alterar a estrutura interna dos ecossistemas vivos, mudando-a em definitivo.

Neste sentido, avaliou-se que a imposição destes novos valores, teria inicialmente por consequência àqueles que se relacionam com a organização, o surgimento de um sentimento de dever de cumpri-los sob uma perspectiva de ética de responsabilização Weber, 1963, p. 97-153), ainda que estes não concordassem com tais valores.

A atualização dos códigos de conduta e o aperfeiçoamento do programa de compliance de forma participativa, cria uma solução de estruturação de ferramentas de transmissão de valores de forma dialogada que viabiliza uma empatia e por conseguinte uma aceitação capaz de uma assimilação pelos que se relacionam com a companhia de forma a tornar possível uma substituição da consciência ética então existente nos indivíduos pelos valores da corporação.

Neste cenário de absorção de valores, temos a inserção do código de conduta da empresa a um viés moral do indivíduo, que insere na sua estrutura de ética da consciência, ou ética interna (Weber, 1963, p. 97-153), os valores, então, imposto pela corporação.

Conclui-se, portanto, que o programa de compliance e o código de conduta das organizações podem ter função que transcende a simples garantia de boas práticas 
empresariais, transcendendo o ambiente de governança corporativa e cumprimento à Lei Anticorrupção (Lei 12.846/13) e pode servir como mecanismo de alteração dos elementos éticos internos do indivíduos relacionados à empresa, contribuindo para que aqueles tenham uma atuação mais íntegra, ética e justa não só quando em atuação dos interesses da empresa, mas também em suas vidas privadas.

\section{REFERÊNCIAS}

BOBBIO, Norberto. Teoria do ordenamento jurídico. Trad. Maria Celeste Santos. 10. ed. Brasília: Editora Universidade de Brasília, 1999.

BRASIL. Lei $\mathrm{n}^{\circ} 12.846$, de $1^{\circ}$ de agosto de 2013. Dispõe sobre a responsabilização administrativa e civil de pessoas jurídicas pela prática de atos contra a administração pública, nacional ou estrangeira, e dá outras providências. Disponível em:

http://www.planalto.gov.br/ccivil_03/_ato2011-2014/2013/lei/112846.htm. Acesso: 03 abr. 2019.

. Decreto $\mathrm{n}^{\circ} 8.420,18$ de março de 2015 . Regulamenta a lei $\mathrm{n}^{\circ} 12.846$ de $1^{\circ}$ de agosto de 2013, dispõe sobre a responsabilização administrativa de pessoas jurídicas pela prática de atos contra a administração pública, nacional ou estrangeira e dá outras providências. Disponível em: http://www.planalto.gov.br/ccivil_03/_Ato20152018/2015/Decreto/D8420.htm Acesso em: 03 abril de 2019.

CARDOSO, Luciane. Código de conduta, responsabilidade empresarial e Direitos Humanos dos trabalhadores. Busca Legis.; Disponível em instituição, como diretriz a ser seguida por todos os seus funcionários29. Um código de conduta é uma declaração formal de valores e práticas corporativas. Acesso em 03 abril 2018. Pag 15896/15897.

CORTINA, Adela. Ética sem moral. Trad. Marcos Marcionilo. São Paulo: Martins Fontes, 2010.

GÜNTHER, Klaus. Teoria da argumentação no direito e na moral: justificação e aplicação. Trad. Cláudio Molz. São Paulo: Landy Editora, 2004.

LUMIA, Giuseppe. Elementos de teoria e ideologia do direito. Trad. Denise Agostinetri. São Paulo: Martins Fontes, 2003.

MATURAMA, Humberto. A árvore do conhecimento. Trad. Jonas Pereira dos Santos.

Campinas: Psy II. 1995. 
RACHELS, James. Os elementos da filosofia moral. Trad. Roberto Cavallari Filho. Barueri: Manole, 2006.

RIBEIRO, Márcia Carla Pereira; DINIZ, Patrícia Ditrich Ferreira. Compliance e a lei anticorrupção nas empresas. Revista de Informação Legislativa, a. 52, n. 205, p.87-105, jan./mar. 2015. Disponível em:

https://www2.senado.leg.br/bdsf/bitstream/handle/id/509944/001032816.pdf?sequence=1 Acesso em 03 abril. 2019. Pag. 90.

VÁZQUEZ, Adolfo Sanchez. Ética. Trad. João Dell anna. 24. ed. Rio de Janeiro: Civilização Brasileira, 2003.

WEBER, Max. A política como vocação. [1918] In GERTH, H. H. \& MILS, Wright (Org.). Ensaios de Sociologia. Trad. Waltensir Dutra. Rio de Janeiro: Ed. Zahar Editores, 1963. Pág. 97 - 153. 